\title{
TU/e EnNHONEN

\section{Inter- and intra-observer variation of fetal volume measurements with three-dimensional ultrasound in the first trimester of pregnancy}

\section{Citation for published version (APA):}

Smeets, N. A. C., van de Ven, J., \& Oei, S. G. (2011). Inter- and intra-observer variation of fetal volume measurements with three-dimensional ultrasound in the first trimester of pregnancy. Journal of Perinatal Medicine, 39(5), 539-543. https://doi.org/10.1515/JPM.2011.054

DOI:

10.1515/JPM.2011.054

Document status and date:

Published: 01/09/2011

\section{Document Version:}

Publisher's PDF, also known as Version of Record (includes final page, issue and volume numbers)

\section{Please check the document version of this publication:}

- A submitted manuscript is the version of the article upon submission and before peer-review. There can be important differences between the submitted version and the official published version of record. People interested in the research are advised to contact the author for the final version of the publication, or visit the $\mathrm{DOI}$ to the publisher's website.

- The final author version and the galley proof are versions of the publication after peer review.

- The final published version features the final layout of the paper including the volume, issue and page numbers.

Link to publication

\footnotetext{
General rights

- You may freely distribute the URL identifying the publication in the public portal. follow below link for the End User Agreement:

www.tue.nl/taverne

\section{Take down policy}

If you believe that this document breaches copyright please contact us at:

openaccess@tue.nl

providing details and we will investigate your claim.
}

Copyright and moral rights for the publications made accessible in the public portal are retained by the authors and/or other copyright owners and it is a condition of accessing publications that users recognise and abide by the legal requirements associated with these rights.

- Users may download and print one copy of any publication from the public portal for the purpose of private study or research.

- You may not further distribute the material or use it for any profit-making activity or commercial gain

If the publication is distributed under the terms of Article 25fa of the Dutch Copyright Act, indicated by the "Taverne" license above, please 


\section{Inter- and intra-observer variation of fetal volume measurements with three-dimensional ultrasound in the first trimester of pregnancy}

\author{
Nicol A.C. Smeets ${ }^{1, *}$, Joost van de $\operatorname{Ven}^{2}$ and \\ S. Guid Oei ${ }^{2,3}$ \\ ${ }^{1}$ Department of Gynecology and Obstetrics, Atrium \\ Medical Center, Parkstad, The Netherlands \\ ${ }^{2}$ Department of Gynecology and Obstetrics, Màxima \\ Medical Center, Eindhoven-Veldhoven, The Netherlands \\ ${ }^{3}$ Department of Electrical Engineering, Eindhoven \\ University of Technology, Eindhoven, The Netherlands
}

\begin{abstract}
Objectives: To determine the inter- and intra-observer variation of volume calculations of human fetuses at a gestational age of $11^{+0}-13^{+6}$ weeks by three-dimensional ultrasound (3DUS).

Methods: 3DUS datasets were acquired during nuchal translucency measurements. The fetal volume (FV) was measured in 65 cases by two independent investigators. The Virtual Organ Computer aided AnaLysis (VOCAL ${ }^{\mathrm{TM}}$ ) imaging software was used to manually calculate the FV (rotational angle $9^{\circ}$ ). Inter- and intra-observer variation were assessed by Bland-Altman plots and intraclass correlation coefficients (ICC).

Results: Both inter- and intraobserver reproducibility were highly reliable as shown by the Bland-Altman plots and an ICC of respectively 0.934 and 0.994 .

Conclusion: FV calculation by 3DUS with VOCAL and a rotational angle of $9^{\circ}$ is feasible and has a high inter- and intraobserver reliability in the first trimester of pregnancy.
\end{abstract}

Keywords: Fetal volume; first trimester; interobserver variation; intraobserver variation; three-dimensional ultrasound.

\section{Introduction}

Monitoring fetal growth during the first trimester of pregnancy might be of value in assessing complications in pregnancy. This is confirmed by the recent study of MookKanamori et al. where first trimester growth restriction was

\footnotetext{
*Corresponding author:

Nicol A.C. Smeets

Atrium Medical Center, Parkstad

Henri Dunantstraat 5, $6401 \mathrm{CX}$

Heerlen, The Netherlands

Tel.: + 31455766513

Fax: +31455766625

E-mail: nss06@atriummc.nl
}

associated with an increased risk of adverse outcomes like preterm birth, low birth weight and small for gestational age at birth [18]. Preterm birth is a growing public health problem with significant consequences for families. Preterm birth accounts for $12.5 \%$ of all births in the US. The costs for the society are an estimated $\$ 26$ billion a year [3]. Low birth weight $(<2500 \mathrm{~g})$ and being small for gestational age are associated with increased morbidity and mortality perinatal and in later life [2, 13].

The difference between normal and abnormal growth in early pregnancy is small, especially when fetal size is measured two-dimensionally by the crown-rump-length (CRL). Three-dimensional ultrasound (3DUS) volume measurements might give more information about fetal development. Earlier reports already confirmed a significant correlation between fetal volume (FV) and the CRL, with an up to 35fold increase of the FV and a 4.5-fold increase of the CRL in the first trimester of pregnancy $[1,6,10,11,14]$. As the $\mathrm{FV}$ increases faster than the CRL in the first trimester, it is possible that early signs of abnormal growth will be more obvious in the FV than in the CRL. Falcon et al. reported that smaller FVs in the first trimester are associated with chromosomal abnormalities [10].

The first attempt to construct three-dimensional (3D) fetal images with ultrasound recordings was performed in the early 1980s [8]. Compared to two-dimensional ultrasound (2DUS), a 3DUS volume scan is acquired faster, is less operator-dependant and calculates volumes of irregular shapes more accurately $[1,4,5,9,11,12,20,21]$. In-vivo studies confirmed these conclusions [9, 12, 16].

Rotational measurement of a volume is possible with the Virtual Organ Computer aided AnaLysis (VOCAL) imaging software, an extension of 3D View $^{\mathrm{TM}}$ (General Electrics Kretz, Zipf, Austria). The VOCAL software allows volume calculation by rotating the object of interest around a central, fixed axis through a number of sequential steps. An experimental study in vitro demonstrated that this technique is more accurate than the multiplanar method for volumetric calculation of irregular shaped objects [21].

In order to calculate the FV, a dataset is obtained during the routine first trimester ultrasound scan. The dataset can easily be obtained when there is a clear mid-sagittal image of the fetus at rest. Then the dataset is stored on a hard disk for offline measurements.

The actual measurement of the fetal volume is more complex, as it is necessary to delineate the fetal contour in many cross sections. A well-known problem of ultrasound in gen- 
eral is the loss of image quality in the deeper layers in the region of interest. Resulting in shadows and blurred edges of the object of interest.

The human factor is also important in volume calculations: the investigator has to decide where to draw the actual edge of the fetal contour in all cross sections of the obtained volume. The investigator needs a steady hand and good concentration. Therefore, it is important to determine the interand intraobserver variation of 3DUS FV measurements before a prospective follow-up study of the relation between $\mathrm{FV}$ and complications in pregnancy.

In this study, we calculated the inter- and intraobserver variation of abdominal 3DUS FV measurements of the fetal head and rump in 65 consecutive pregnant women with a gestational age of $11^{+0}-13^{+6}$ weeks.

\section{Materials and methods}

This was a prospective cohort study, performed at the Máxima Medical Center, a teaching hospital in Eindhoven-Veldhoven, The Netherlands. The protocol was approved by the Institutional Medical Ethics Committee and informed consent was obtained prior to inclusion in this study.

The Kretz Voluson 730 3D ultrasound scanner (General Electrics Kretz, Zipf, Austria) was used with the RAB4-8P wide band convex volume probe, a real-time 4D-broadband electronic curved-array transducer with a frequency range of 4-8 MHz. The angle sweep was $75^{\circ}$.

The $3 \mathrm{D}$ volumes were acquired during the standard (abdominal) first trimester scan by an investigator (investigator I) certified for nuchal translucency (NT) measurements. The gestational age was established by menstrual dates and confirmed by routine fetal biometry.

Inclusion criteria were: Singleton pregnancy, age $>18$ years, gestational age between $11^{+0}$ and $13^{+6}$ weeks. Exclusion criteria were: Multiple pregnancy and an uncertain gestational age. Patients were included after signing an informed consent form. Each patient completed a questionnaire about their general and obstetric history.

For volume acquisition the fetus had to be motionless during scanning. The time needed to acquire each dataset was registered.

First, a routine first trimester (abdominal) ultrasound scan was performed according to the Dutch national guidelines [19]. The NTmeasurement was performed according to the guidelines of the Fetal Medicine Foundation [22].

3D View ${ }^{\mathrm{TM}}$ (General Electronics, Sonoview II) was used to receive, store digitally and measure the FVs from the 3DUS-datasets. After obtaining the ideal plane for NT-measurement, an automatic 3DUS sweep was performed, which consisted of multiplanar and surface reconstruction modes. The acquired datasets were collected and stored on a hard disk for offline processing and volume calculation. Investigators II and III performed the volume calculations, they were used to working with the VOCAL program and blinded for the results of the first trimester scan.

The VOCAL imaging software (an extension of 3D View ${ }^{\mathrm{TM}}$ ) consists of several available modes for volume calculations, the "manual mode" is the most frequently used. This mode is more flexible as it manually defines the contours of the object of interest with a computer mouse. As the human embryo has an irregular shape, the manual mode was used to outline the region of interest (ROI), the fetal head and rump, in all cross sections. It is not possible to include the fetal extremities in these measurements, because the software does not allow to define separate structures in one cross section. Therefore, the ROI has to consist of one continuous object in every cross section.

With VOCAL it is possible to use four different rotational steps that define the angle through which the object of interest is rotated. These steps are $6^{\circ}, 9^{\circ}, 15^{\circ}$ or $30^{\circ}$, which results in respectively 30 , 20,12 or 6 cross sections for each volume measurement, as the dataset is rotated $180^{\circ}$ to complete one volume measurement.

The FVs were calculated with a rotational step of $9^{\circ}$ in the A(axial)-plane, which is a longitudinal plane. This $9^{\circ}$ rotation is to be preferred in irregular objects, as it is as reliable as the $6^{\circ}$ rotation, but significantly faster to perform [21].

The $9^{\circ}$ rotational step results in a sequence of 20 longitudinal sections of the fetus around a fixed axis. In each of these planes the two-dimensional (2D) contour of the fetus (excluding the limbs) was defined manually, as described by others [11, 14, 15]. The VOCAL program then calculates the volume of the defined contour. After calculation the computed reconstruction of the fetus is displayed together with the FV (Figure 1). The undulating surface of the $3 \mathrm{D}$ image is caused by the rotational steps and represents the ROIs in each measured plane. The dataset was of inadequate quality when the fetal contour was unclear in any rotational plane, so it was not possible to calculate the FV.

In 65 consecutive cases, the FV was measured by two independent investigators (interobserver variation). The measurements were repeated by one of the investigators in a second session (intraobserver variation). This investigator was blind to the results of the first measurements. The time needed for each volume calculation was registered.

The inter- and intraobserver variation was analyzed by the method described by Bland and Altman [7], by calculating the intraclass correlation coefficient (ICC) and the $95 \%$ confidence intervals (95\% $\mathrm{CI})$. The ICC is defined as the correlation between two measurements from the same subject. It varies from 0 to 1 , which indicates the maximum reliability. Values above 0.70 are usually accepted as good ICC. For the statistical analysis SPSS ${ }^{\mathrm{TM}}$ (Chicago, IL, USA) version 13.0 for Windows was used.

\section{Results}

In total 65 consecutive FV scans were analyzed. Fifty datasets $(76.9 \%)$ were of adequate quality for volume calculations. The image was considered of inadequate quality when it was not possible to define the fetal contour in any rotational plane (for example blurred edges). Inadequate image quality was caused by maternal overweight, body mass index $($ BMI $)>30,(n=4 / 15,26.7 \%)$ and fetal movements $(n=6 /$ $15,40 \%)$. Another reason for failure was an unfavorable position of the fetus during scanning $(n=5 / 15,33.3 \%)$, for example when the fetus lies partially against the uterine wall. Then, it is impossible to distinguish the fetal contour from the surrounding structures. Several of these datasets show an initial clear $2 \mathrm{D}$ image, but after rotating the fetal image it becomes unclear.

The average maternal age was 33.4 years (range: 1741 years). The mean gestational age was $12^{+3}$ weeks (range: $11^{+3}-13^{+3}$ weeks). The mean measured volume was $19.57 \mathrm{~cm}^{3}$ (range: $8.35-36.85 \mathrm{~cm}^{3}$ ). Figure 2 shows the average measurements of observer I and the measurements of observer II. The $\mathrm{X}$-axis represents the gestational age (days), the Y-axis the measured FV $\left(\mathrm{cm}^{3}\right)$.

Figure 3 shows the Bland-Altman plot of the two sets of fifty FV measurements by observer II. The mean difference 


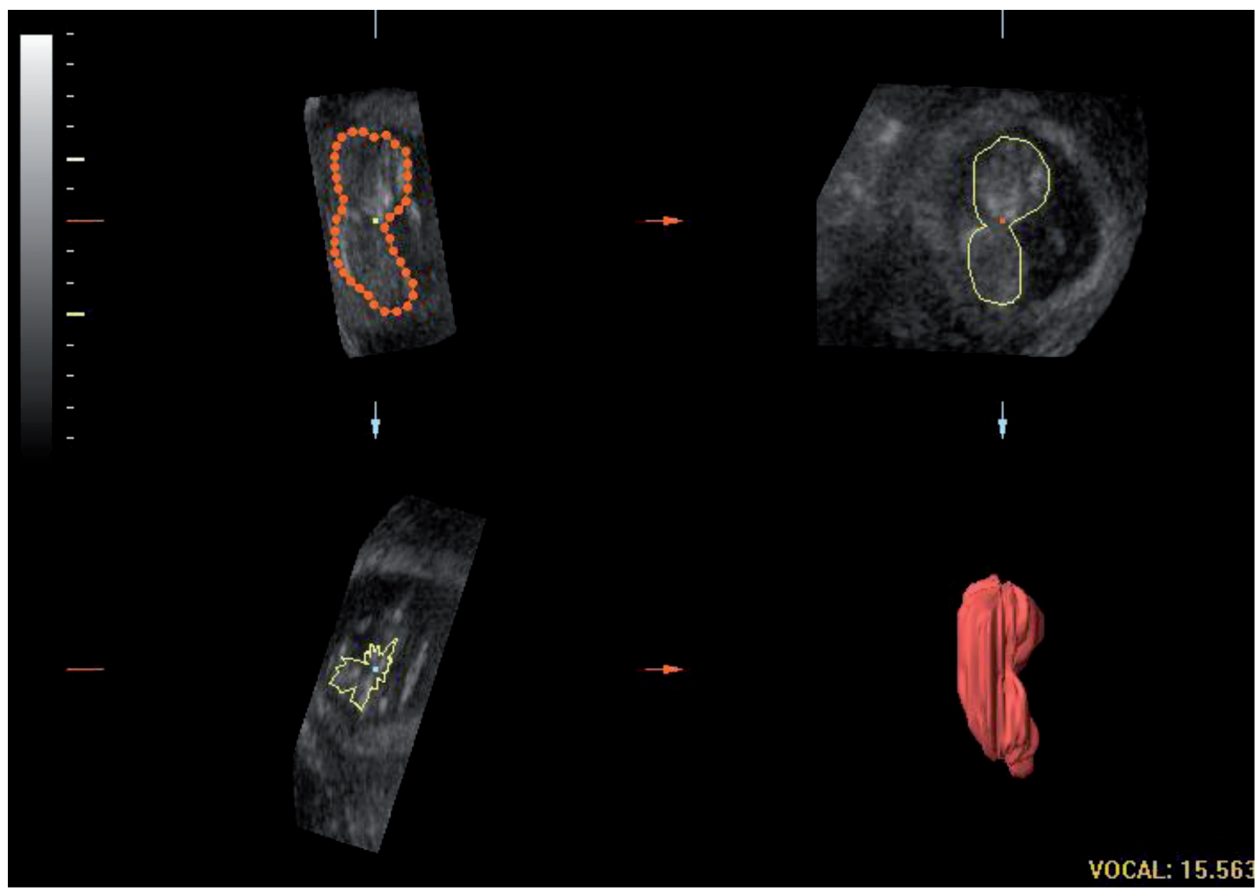

Figure 1 Three-dimensional fetal volume calculation with the VOCAL imaging program (volume in $\mathrm{cm}^{3}$ ). VOCAL $=$ Virtual Organ Computer aided AnaLysis.

is $0.11 \mathrm{~cm}^{3}$ with a $95 \%$ CI between -1.29 and $+1.50 \mathrm{~cm}^{3}$. There is an equal pattern of scattering around the mean in the FV measurements of observer II. Figure 4 shows the data regarding the mean of the two sets of measurements by observer II and the measurements by observer III. The mean difference is $-1.42 \mathrm{~cm}^{3}$ with a $95 \%$ CI between -5.76 and $+2.93 \mathrm{~cm}^{3}$. There is also an equal pattern of scattering. There is a trend that observer III measures larger volumes in smaller fetuses than observer I.

To assess the reproducibility of the FV measurements with 3DUS the ICC was calculated. The volume measurements of the two different observers (interobserver reliability) were

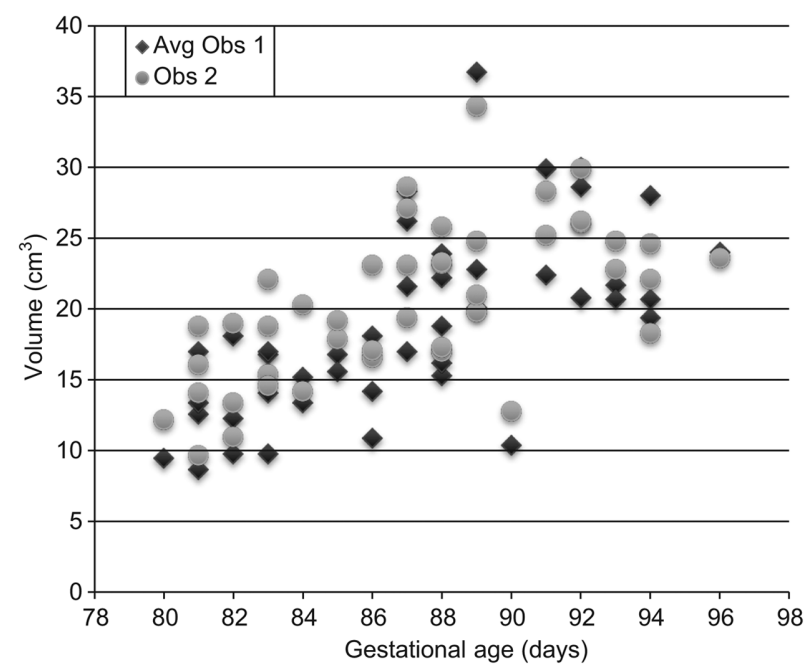

Figure 2 The fetal volumes measured by the observers, gestational age in days. highly reliable; ICC: 0.934 (95\% CI: 0.887-0.962). The intraobserver reproducibility had even a higher grade of reliability; ICC: 0.994 (95\% CI: 0.990-0.997).

3DUS volume scans were acquired during NT measurements. The mean time to perform the 2DUS scanning (NT measurement) was 14 min (range: 10-18 min). Mean time for the subsequent acquisition of the 3DUS volumes was 5 min (range: $3-7 \mathrm{~min}$ ). With the 3DUS volumes, the mean

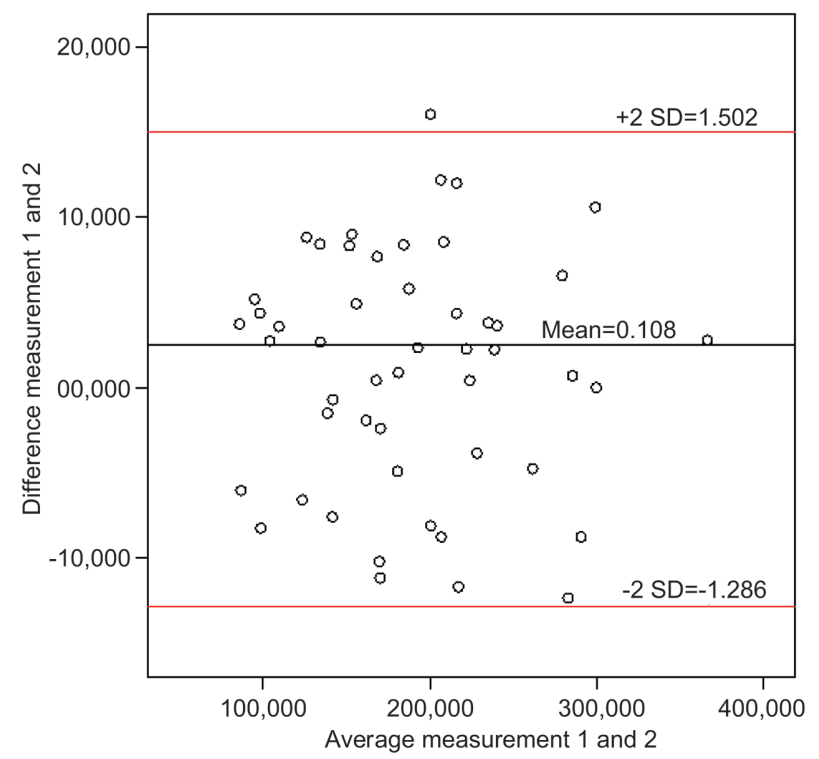

Figure 3 Bland-Altman plot of 3DUS volume measurements by observer 1 (intraobserver variation). On the $\mathrm{x}$ - and $\mathrm{y}$-axis fetal volumes in $\mathrm{cm}^{3}$.

$3 \mathrm{DUS}=$ three-dimensional ultrasound. 


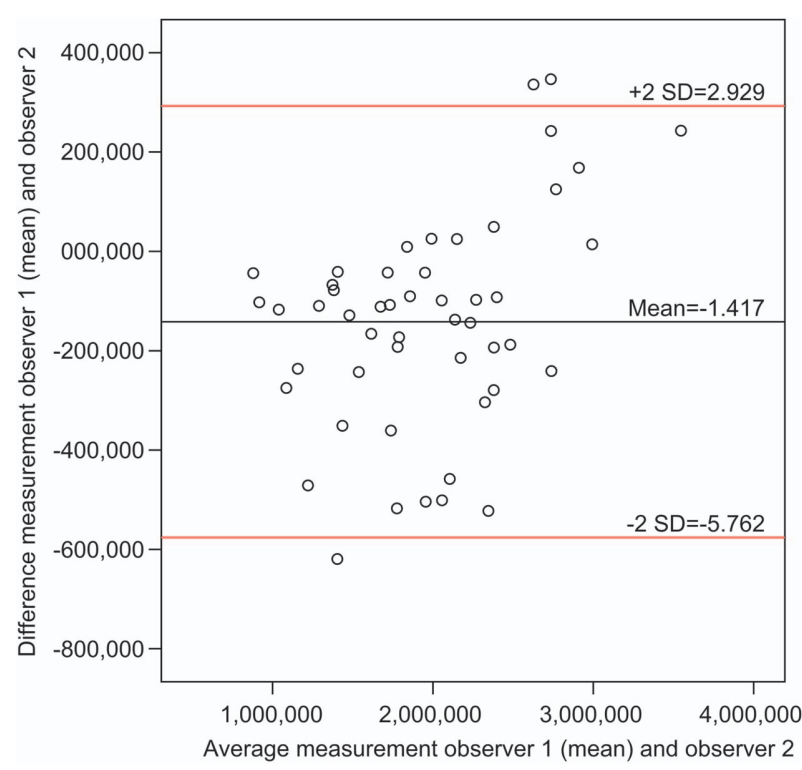

Figure 4 Bland-Altman plot of 3DUS volume measurements by observer 1 and 2 (interobserver variation). On the $\mathrm{x}$ - and $\mathrm{y}$-axis fetal volumes in $\mathrm{cm}^{3}$.

3DUS $=$ three-dimensional ultrasound, $\mathrm{SD}=$ standard deviation

time needed to perform the offline FV measurement was 4 min (range: $3-5 \mathrm{~min}$ ).

\section{Discussion}

Several authors reported FV measurements [6, 11, 14, 15, 17], most of them also used the commercially available VOCAL software $[6,11,15,17]$. In this program, it is technically impossible to measure several objects in one image. Therefore, it is not possible to measure FV with the limbs included as there is always an image in which the limbs are not continuous with the fetal rump or face. Blaas et al. [6] used Vingmed EchoPAC-3D software for measurement of the FV, with this method is was possible to include the limbs in the volume measurements. They reported that the limbs represent $5-10 \%$ of the total volume. They found a poor interobserver variation regarding the fetal limb measurements.

Aviram et al. [1] measured the FV with the limbs included and reported only that there were no significant differences between the examiners. Falcon et al. [11] reported no ICC, the mean measurement difference regarding the intraobserver variation seems to be higher $(-0.087$ vs. 0.11$)$ with a broader range in measured differences $(-3.18$ to 4.92 vs. -1.29 to 1.50). The interobserver variation in their report appears to be lower $(-1.09$ vs. -1.42$)$, but there is also a broader range in measured differences ( -6.70 to 4.53 vs. -5.76 to 2.93 ). Both studies show good intra- and interobserver variations for FV measurements. The smaller range in measurements in our study might be due to the smaller rotational angle.

Raine-Fenning et al. showed the impact of the different available rotational angles using the VOCAL software
$[20,21]$. Their conclusion was that volume measurements of irregular objects were more reliable with a rotational angle of $6^{\circ}$ or $9^{\circ}$. Earlier inter- and intraobserver variation studies of $\mathrm{FV}$ were performed with a rotational angle of $30^{\circ}$ $[1,6,11]$.

Inter- and intraobserver reproducibility of FV by 3DUS appears to be highly reliable, with a very good ICC of 0.934 and 0.994, respectively. Despite a trend to measure larger volumes by one of the observers (Figure 4) there is a high reliability between the two observers' measurements. This is probably caused by the fixed axis (as a point of reference in the VOCAL imaging program) and clear difference in gray scale on the ultrasound scans between fetus and amniotic fluid environment.

However, in 15 cases $(23 \%)$ the image quality was insufficient for FV calculations. The main reasons for failure of the FV measurements were fetal movements during ultrasound scanning $(n=6 / 15 ; 40 \%)$ and an unfavorable fetal position of the fetus $(n=5 / 15 ; 33.3 \%)$. In these 11 scans, the initial 2DUS image was of good quality. After rotating the volume box, the fetal contours became unclear, resulting in failure of FV measurement. Obesity $(n=4 / 15 ; 26.7 \%)$ was also a reason for poor image quality and in these cases the general 2DUS scan was also difficult to perform. Vaginal ultrasound might be a good alternative option.

The image quality of the whole volume box should always be checked before the end of the exam, even with a perfect 2DUS image. Then, if the volume box is of inadequate quality, rescanning the patient is still possible. It is to be expected that future enhancements of acquisition time will result in further improvement of image quality and less artefacts caused by fetal movement. These points will result in less failure of FV measurements.

Assessment of normal values of 3DUS FV measurements in pregnant women with a gestational age of $11^{+0}-13^{+6}$ weeks is feasible. The inter- and intraobserver agreement of fetal volumetry by 3DUS is very high. A small rotational angle of $9^{\circ}$ results in an acceptable range of measured volumes.

\section{References}

[1] Aviram R, Kamar Shpan D, Markovitch O, Fisherman A, Tepper R. Three-dimensional first trimester fetal volumetry; comparison with crown rump length. Early Hum Dev. 2004;80: $1-5$.

[2] Barker DJP. Mothers, babies and disease in later life. 2nd ed. Churchill Livingstone; 1998.

[3] Behrman RE, Stith Butler A, Committee on Understanding Premature Birth and Assuring Healthy Outcomes. Preterm birth: causes, consequences, and prevention; 2006.

[4] Benacerraf BR, Shipp TD, Bromley B. Three-dimensional US of the fetus: volume imaging. Radiology. 2006;238:988-96.

[5] Blaas HG, Eik-Nes SH, Berg S, Torp H. In-vivo three-dimensional ultrasound reconstructions of embryos and early fetuses. Lancet. 1998;352:1182-6.

[6] Blaas HGK, Taipale P, Torp H, Eik-Nes SH. Three-dimensional ultrasound volume calculations of human embryos and 
young fetuses: a study on the volumetry of compound structures and its reproducibility. Ultrasound Obstet Gynecol. 2006;27:640-6.

[7] Bland JM, Altman DG. Statistical methods for assessing agreement between two methods of clinical measurement. Lancet. 1986;1:307-10.

[8] Brinkley JF, McCallum WD, Muramatsu SK, Liu DY. Fetal weight estimation from ultrasonic three-dimensional head and trunk reconstruction: evaluation in vitro. Am J Obstet Gynecol. 1982;144:715-21.

[9] Chang FM, Liang RI, Ko HC, Yao BL, Chang CH, Yu CH. Three-dimensional ultrasounds-assessed fetal thigh volumetry in predicting birth weight. Obstet Gynecol. 1997;90:331-9.

[10] Falcon O, Peralta CFA, Cavoretto P, Auer M, Nicolaides KH. Fetal trunk and head volume in chromosomally abnormal fetuses at $11^{+0}$ to $13^{+6}$ weeks of gestation. Ultrasound Obstet Gynecol. 2005;26:517-20.

[11] Falcon O, Peralta CF, Cavoretto P, Faiola S, Nicolaides KH. Fetal trunk and head volume measured by three-dimensional ultrasound at $11^{+0}$ to $13^{+6}$ weeks of gestation in chromosomally normal pregnancies. Ultrasound Obstet Gynecol. 2005; 26:263-6.

[12] Junior EA, Guimaraes Filho AH, Pires CR, Nardozza LM, Moron AF, Mattar R. Validation of fetal cerebellar volume by three-dimensional ultrasonography in Brazilian population. Arch Gynecol Obstet. 2007;275:5-11.

[13] Kramer MS. Determinants of low birth weight; methodological assessment and meta-analysis. Bul World Health Organ. 1987;65:663-737.

[14] Martins WP, Ferriani RA, Nastri CO, Filho FM. First trimester fetal volume and crown-rump length: comparison betweens singletons and twins conceived by in vitro fertilization. Ultrasound Med Biol. 2008;34:1360-4.

[15] Martins WP, Nastri CO, Barra DA, Navarro PAAS, Filho FM, Ferriani RA. Fetal volume and crown-rump length from 7 to
10 weeks of gestational age in singletons and twins. Eur $\mathrm{J}$ Obstet Gynecol Reprod Biol. 2009;145:32-5.

[16] Michailidis GD, Papageorgiou P, Economides DL. Assessment of fetal anatomy in the first trimester using two- and three-dimensional ultrasound. Br J Radiol. 2002;75:215-9.

[17] Moeglin D, Talmant C, Duyme M, Lopez AC, Collège Français d'Echographie Foetal. Fetal lung volumetry using two and three-dimensional ultrasound. Ultrasound Obstet Gynecol. 2005;25:119-27.

[18] Mook-Kanamori DO, Steegers EAP, Eilers PH, Raat H, Hofman A, Jaddoe VWV. Risk factors and outcomes associated with first-trimester fetal growth restriction. J Am Med Assoc. 2010;303:527-34.

[19] Nederlandse Vereniging voor Obstetrie en Gynaecologie, Modelprotocol Nekplooimeting; 2005, www.nvog.nl.

[20] Raine-Fenning N, Cambell B, Collier J, Brincat M, Johnson I. The reproducibility of endometrial volume acquisition and measurement with the VOCAL-imaging program. Ultrasound Obstet Gynecol. 2002;19:69-75.

[21] Raine-Fenning NJ, Clewes JS, Kendall NR, Bunkheila AK, Campbell BK, Johnson IR. The interobserver reliability and validity of volume calculation from three-dimensional ultrasounds datasets in the in vitro setting. Ultrasound Obstet Gynecol. 2003;21:283-91.

[22] The Fetal Medicine Foundation, the 11-13 weeks scan. http://www.fetalmedicine.com/fmf/online-education/01-11136-week-scan.

The authors stated that there are no conflicts of interest regarding the publication of this article.

Received October 19, 2010. Revised February 26, 2011. Accepted March 15, 2011. 